\title{
Expanding the Scope: Beyond the Familiar and Beyond the Page
}

\author{
Donald A. Hantula ${ }^{1}$
}

Published online: 7 October 2016

(C) Association for Behavior Analysis International 2016

With this issue, we continue to shape $T B A$ into a scholarly journal befitting its place as ABAI's flagship publication. We are moving forward with new policies streamlining ethics disclosures and the criteria for types of articles that $T B A$ will publish. This issue features papers that expand the scope of behavior analysis, tutor us in advances in behavioral theory, and take us beyond the page. We hope that these articles and new formats will instruct and inspire even better research or applied work.

\section{TBA Policy Changes}

Beginning with this issue, we will institute two policy changes. One concerns conflict of interest and ethics, and the other reduces and redefines the types of articles that will appear in $T B A$.

Conflict of Interest and Ethics We have rewritten the conflict of interest and ethics disclosure for $T B A$ to make it more relevant to the papers that $T B A$ publishes. All authors must disclose any potential conflicts of interest and funding sources. Papers that do not report primary data collection will no longer have to provide confirmation that the research was reviewed and approved by an IRB, IACUC, or equivalent committee or governing body.

In order to promote transparency and avoid any appearance of conflict of interest in the review process, I will appoint an independent guest associate editor to handle any submissions from the editor or associate editors. For example, Associate Editor Tom Critchfield coauthored a paper in the current issue that was handled by guest associate editor Phil Hineline. In some cases, an independent guest associate editor will also handle papers submitted by

Donald A. Hantula

hantula@temple.edu

1 Department of Psychology, Weiss Hall, Temple University, 1701 N 13 St, Philadelphia, PA 19122-6085, USA 
editorial board members. In all cases, the guest associate editor will have full authority and independence in the review process and in decisions regarding publication.

Types of Articles We seek to simplify the submission process for authors and the review process for referees. TBA submissions will be classified in the following categories.

Editorial These papers will introduce issues and special section of issues. They will be reviewed and edited by the editor or associate editors.

Announcement These will acknowledge guest reviewers and associate editors, advertise special issues, and communicate any news relevant to TBA readers.

In Memoriam $T B A$ will continue to pay tribute to influential behavior analysts who have passed on. These papers may be solicited by the editor or submitted and will be reviewed and edited by the editor or associate editors.

Book Review TBA welcomes reviews of books on behavior analysis, or books relevant to behavior analysis. Book reviews will be reviewed and edited by the editor or associate editors and sent out for further review at their discretion.

Commentary These submissions will include short articles and the former "on terms" type papers. The title of these latter submissions should begin with the phrase "On terms:" These submissions will be sent out for full review.

Original Research Most TBA articles will fall into this category. Those submissions that pass an initial screening by the editor will be assigned to an associate editor and sent out for full review. TBA has a tradition of publishing expert tutorials that we will continue to uphold. Tutorials will be included in this category, and the title of such papers should begin with the word "Tutorial:" We recognize that the term "research" may mean "empirical study" to many in the behavior analytic scholarly community; however, we also recognize that behavior analysis has a long history of theoretical and conceptual research. The difference between the two approaches is merely in the methods. Whether one uses data or concepts, good research and scholarship demand equally rigorous reasoning processes.

\section{Updating the Publication Process}

Articles accepted for publication in TBA will appear on the TBA section of the Springer website as soon as the final proofing is complete. These articles may then be accessed through the Springer website and by many library databases, read, downloaded, and cited. The 6th edition of the APA style manual states that the article doi should be used in place of volume, issue and page numbers, when citing such advance electronic copies of an article, e.g.

Kaplan, B. A., Amlung, M., Reed, D. D., Jarmolowicz, D. P., McKerchar, T. L., \& Lemley, S. M. (2016). Automating scoring of delay discounting for the 21- and 27- 
item monetary choice questionnaires. The Behavior Analyst, doi:10.1007/s40614016-0070-9.

\section{In This Issue}

Expanding the Scope Many behavior analysts seem to be skeptical of, if not entirely opposed to neuroscience. Granted, as the infamous "dead salmon" study (Bennett, Miller, \& Wolford, 2009) showed quite comically and persuasively, data from neuroscience studies can lead to wildly different conclusions if not analyzed properly. These issues of replication and reality in neuroscience research continue, whether they involve fMRI studies (Eklund, Nichols, \& Knutsson, 2016), tDCS (Vannorsdall et al., 2016), or other technologies. Often neuroscience research, its accompanying apparatus and administrators, can appear reminiscent of the scene featuring the machine that goes ping! in Monty Python's classic film The Meaning of Life. However, it also seems that many behavior analysts may base their aversion to neuroscience research on a misunderstanding of Skinner's writings on the topic. Zilio's paper in this issue illuminates and contextualizes Skinner's criticisms of neuroscience. Scientific skepticism, especially when new technologies are involved, is a prudent practice. However, it is equally imprudent to dismiss all neuroscience data and ignore its possibilities for behavioral research based on either misunderstanding or clinging to antiquated arguments. Indeed, as research shows, behavior analysis and neuroscience can inform one another (Schlund \& Cataldo, 2005; Strumwasser, 1994; Timberlake, Schaal, \& Steinmetz, 2005), providing more complete answers to research questions ranging from mouse models of schizophrenia (Ward, Simpson, Kandel, \& Balsam, 2011), equivalence relations (Haimson, Wilkinson, Rosenquist, Ouimet, \& McIlvane, 2009), gambling (Dixon, Wilson, \& Habib, 2014; Dymond et al., 2014; Habib \& Dixon, 2010), cocaine use (Rebec \& WenLin, 2005), classical conditioning (VilliarreaI \& Steinmetz, 2005), and theoretical advances (Jarmolowicz, Reed, DiGennaro Reed, \& Bickel, 2016).

The science of behavior analysis is the foundation for behavioral interventions. But what undergirds the science? Grounded in modern philosophy (Quine, 1960; Rorty, 1989), Schoneberger revisits the realism/pragmatism debate is the essence of behavioral metatheory and expands on the idea of behavioral pragmatism (Barnes-Holmes, 2000, 2004, 2005) to show how Rorty's work can be used as a means to incorporate both reality and truth into a coherent behavioral philosophy. Does it work? How will we know? These are the next steps.

Behavior analysis research and practice has been intertwined with developmental issues for many decades (Bijou, 1993, 1996); more recently, it has found common cause with systems analysis (Abernathy, 2014; Diener, McGee, \& Miguel, 2009). Moore's paper is a lucid demonstration of the ways in which developmental systems theory and behavior analytic theory are mutually compatible. In particular, both approaches reject a "black box" view of causality and instead look to contextually based explanations of behavior. Moore's paper is both theoretically important as well as practically important in that it provides a rich background for behavior analysts who work in developmental disabilities to reconceptualize strategies for effective intervention. 
How To Do It We are fortunate to feature two expert tutorials this issue. In the first tutorial, Rachlin presents an expanded view of self-control that goes beyond a momentary choice to engage in a particular act to incorporate patterns of acts extended over time, which Rachlin calls soft commitment (Siegel \& Rachlin, 1995). Rachlin's work on self control has developed from basic operant laboratory experiments (Rachlin \& Green, 1972) to social cooperation (Rachlin, 2016) and to soft commitment. The second tutorial by Greer, Fisher, Romani, and Saini provides an up to date summary of behavioral momentum theory and its implications for application (Nevin, Mandell, \& Atak, 1983; Nevin \& Shahan, 2011). Just like Rachlin's work on self control, behavioral momentum theory has its genesis in the operant laboratory (Nevin et al., 1983) This tutorial takes us beyond the page and features an innovative set of Microsoft Excel-based learning activities that can be downloaded as supplementary materials.

Delay discounting emerged from the operant lab (Ainslie \& Herrnstein, 1981) to become one of the most highly research topics in behavior analysis and beyond. Indeed, it now appears that there are more delay discounting studies conducted outside of behavior analysis than within the behavior analytic tradition. One possible reason for this relative lack of research is the perceived difficulty of the mathematics needed to analyze these data. Quantitative tools and analyses have certainly advanced behavioral research and theory (see for example the preceding two articles in this issue), but perhaps an over-reliance on solely visual analysis of graphed data has delayed the field's further development (Fisher \& Lerman, 2014). Kaplan, Amlung, Reed, Jarmolowicz, McKerchar, and Lemley provide a Microsoft Excel-based tool that automates scoring of the Hypothetical Monetary Choice Questionnaire, perhaps the most commonly used method to study delay discounting. This tool, which may be downloaded from the KU Scholarworks website, should prove useful to all delay discounting researchers, experienced or new. This paper raised an important question among the reviewers and editors. Is it appropriate for $T B A$ ? Of course, its appearance in this issue answers the question affirmatively. TBA has published methodological papers in the past (Springer, Brown, \& Duncan, 1981) and welcomes more methodological papers.

Research and scholarship are no longer limited words and figures printed on paper. In this issue, both a tutorial and a methodological paper provide links to online material that make these articles more compelling and useful. The lead article in the previous issue of TBA consisted of QR codes (Keenan, 2016) that linked to videos. Last issue's editorial asked if TBA should remain tied to atoms or if it should embrace bits (Hantula, 2016). All of these papers take us beyond the page, a practice that we should continue.

How should we speak and write about behavior analysis, both when communicating within behavior analysis or with the members of the general population is an ongoing concern in the field (Diller, Salters-Pedneault, \& Gallagher, 2014; Freedman, 2016; Friman, 2014a, 2014b; Hayes, 1991; Hineline, 2005; Morris, 1985, 2014; Reed, 2014; Smith, 2016; Tuomisto \& Parkkinen, 2012). Rather than present another discussion article or tutorial, Becirevic, Critchfield, and Reed asked the general public's opinion about behavioral terminology and possible alternatives. A paper reporting data is a rarity in $T B A$, and again questions about its appropriateness for the journal were raised. It was agreed that this paper's purpose was not to report primary data (as is most often the case with empirical papers), but rather to use a data collection exercise to illuminate larger conceptual 
issues. The findings are important for any behavior analytic practitioner or teacher working to communicate with the general public. They found that often used terms such as "chaining," "escape extinction," and "negative reinforcement" are not viewed as acceptable sounding treatments for nearly all potential client groups. However "reinforcement" was generally viewed positively. Apparently, people like reinforcement. On the other hand, precision matters more when communicating within behavior analysis. Merbitz, Merbitz, and Pennypacker present a short but important paper arguing for a more consistent use of the term "frequency." Similarly, DeQuinzio, Poulson, Townsend, and Taylor's take on social referencing in children with autism demystifies the concept and instead defines it as a two-step chain and present some treatment and research implications of their analysis. Layng's review of Suskind's book 30 Milion Words relates not only an uplifting and optimistic story of how a surgeon discovered behavior analysis through Hart and Risley's pioneering volume but also how behavior analysts can further contribute to this work.

\section{In Memoriam}

The issue ends on a sad note with Peter Killeen's very personal and moving tribute to his friend and colleague, Edmund Fantino, who passed away in November 2015. Professor Fantino was one of the most innovative, productive, and influential scholars in our field's history. He developed the Delay Reduction Hypothesis (Fantino, 1969), a simple, yet powerful account of delay to reinforcement and choice which he extended beyond the operant lab to foraging (Fantino \& Abarca, 1985) and to human choice and decision-making (Fantino, 1998a), including an account of why he found the information display panel on his new Toyota Prius so fascinating (Fantino, 2008). These two conceptual leaps may be his enduring legacy. Professor Fantino eloquently showed the commonalities between basic operant research and theory and foraging theory and behavioral ecology (Abarca, Fantino, \& Ito, 1985; Fantino, 1985, 1991; Fantino \& Abarca, 1985; Fantino \& Preston, 1988), sparking a vigorous stream of research that continues to this day, including applications in addictions (Bickel, Giordano, \& Badger, 2004) and consumer behavior (Hantula, 2012). His ventures into human judgment and decision-making provide a cogent counterpoint to the ubiquitous "heuristics and biases" literature, demonstrating how fundamental operant principles can explain decision "errors" and logical fallacies (Fantino, 1998b; Fantino, Kulik, Stolarz-Fantino, \& Wright, 1997; Fantino \& Stolarz-Fantino, 2008; Fantino, Stolarz-Fantino, \& Navarro, 2003) such as base rate errors (Goodie \& Fantino, 1996), the conjunction fallacy (Fantino et al., 1997), and sunk cost (Navarro \& Fantino, 2005, 2009). In his later years, Professor Fantino focused his behavioral acumen on more applied questions such as how "mindfulness meditation" can increase false memories (Wilson, Mickes, Stolarz-Fantino, Evrard, \& Fantino, 2015) and how a soda tax may backfire (Wilson, Stolarz-Fantino, \& Fantino, 2013). Readers who are unfamiliar with Professor Fantino's impressive work are invited to read some of the papers referenced above, or some of his other $100+$ publications. 


\section{References}

Abarca, N., Fantino, E., \& Ito, M. (1985). Percentage reward in an operant analogue to foraging. Animal Behaviour, 33(4), 1096-1101.

Abernathy, W. B. (2014). Beyond the Skinner box: the design and management of organization-wide performance systems. Journal of Organizational Behavior Management, 34(4), 235-254.

Ainslie, G., \& Herrnstein, R. J. (1981). Preference reversal and delayed reinforcement. Animal Learning \& Behavior, 9(4), 476-482.

Barnes-Holmes, D. (2000). Behavioral pragmatism: no place for reality and truth. The Behavior Analyst, 23(2), 191-202.

Barnes-Holmes, D. (2004). A reply to Leigland's 'Is a new version of philosophical pragmatism necessary? A reply to Barnes-Holmes'. The Behavior Analyst, 27(1), 113-116.

Barnes-Holmes, D. (2005). Behavioral pragmatism is a-ontological, not antirealist: a reply to Tonneau. Behavior and Philosophy, 33, 67-79.

Bennett, C. M., Miller, M., \& Wolford, G. (2009). Neural correlates of interspecies perspective taking in the postmortem Atlantic salmon: an argument for multiple comparisons correction. NeuroImage, 47(Suppl 1), S125.

Bickel, W. K., Giordano, L. A., \& Badger, G. J. (2004). Risk-sensitive foraging theory elucidates risky choices made by heroin addicts. Addiction, 99(7), 855-861.

Bijou, S. W. (1993). Behavior analysis of child development, 2nd rev. Reno: Context Press.

Bijou, S. W. (1996). Reflections on some early events related to behavior analysis of child development. The Behavior Analyst, 19(1), 49-60.

Diener, L. H., McGee, H. M., \& Miguel, C. F. (2009). An integrated approach for conducting a behavioral systems analysis. Journal of Organizational Behavior Management, 29(2), 108-135.

Diller, J. W., Salters-Pedneault, K., \& Gallagher, A. R. (2014). Effective dissemination requires effective talk: a comparison of behavior-analytic journals. Behavior Analysis in Practice, 7(2), 103-106.

Dixon, M. R., Wilson, A., \& Habib, R. (2014). Neurological correlates of slot machine win size in pathological gamblers. Behavioural Processes, 104, 108-113.

Dymond, S., Lawrence, N. S., Dunkley, B. T., Yuen, K. S. L., Hinton, E. C., Dixon, M. R., et al. (2014). Almost winning: induced MEG theta power in insula and orbitofrontal cortex increases during gambling near-misses and is associated with BOLD signal and gambling severity. NeuroImage, 91, 210-219.

Eklund, A., Nichols, T. E., \& Knutsson, H. (2016). Cluster failure: why fMRI inferences for spatial extent have inflated false-positive rates. Proceedings of the National Academy of Sciences, 113(28), 7900-7905.

Fantino, E. (1969). Choice and rate of reinforcement. Journal of the Experimental Analysis of Behavior, 12(5), $723-730$

Fantino, E. (1985). Behavior analysis and behavioral ecology: a synergistic coupling. The Behavior Analyst, $8(2), 151-157$

Fantino, E. (1991). Behavioral ecology. In I. H. Iversen \& K. A. Lattal (Eds.), Experimental analysis of behavior, parts $1 \& 2$ (pp. 117-153). New York,: Elsevier Science.

Fantino, E. (1998a). Behavior analysis and decision making. Journal of the Experimental Analysis of Behavior, 69(3), 355-364.

Fantino, E. (1998b). Judgment and decision making: behavioral approaches. The Behavior Analyst, 21(2), 203-218.

Fantino, E. (2008). Choice, conditioned reinforcement, and the Prius effect. The Behavior Analyst, 31(2), 95111.

Fantino, E., \& Abarca, N. (1985). Choice, optimal foraging, and the delay-reduction hypothesis. Behavioral and Brain Sciences, 8(2), 315-362.

Fantino, E., Kulik, J., Stolarz-Fantino, S., \& Wright, W. (1997). The conjunction fallacy: a test of averaging hypotheses. Psychonomic Bulletin \& Review, 4(1), 96-101.

Fantino, E., \& Preston, R. A. (1988). Choice and foraging: the effects of accessibility on acceptability. Journal of the Experimental Analysis of Behavior, 50(3), 395-403.

Fantino, E., \& Stolarz-Fantino, S. (2008). Gambling: sometimes unseemly; not what it seems. Analysis of Gambling Behavior, 2(2), 61-68.

Fantino, E., Stolarz-Fantino, S., \& Navarro, A. (2003). Logical fallacies: a behavioral approach to reasoning. The Behavior Analyst Today, 4(1), 109-117.

Fisher, W. W., \& Lerman, D. C. (2014). It has been said that, "there are three degrees of falsehoods: lies, damn lies, and statistics'. Journal of School Psychology, 52(2), 243-248.

Freedman, D. H. (2016). Improving public perception of behavior analysis. The Behavior Analyst, 39(1), 8995. 
Friman, P. C. (2014a). Behavior analysts to the front! A 15-step tutorial on public speaking. The Behavior Analyst, 37(2), 109-118.

Friman, P. C. (2014b). Publishing in journals outside the box: attaining mainstream prominence requires demonstrations of mainstream relevance. The Behavior Analyst, 37(2), 73-76.

Goodie, A. S., \& Fantino, E. (1996). Learning to commit or avoid the base-rate error. Nature, 380(6571), 247249.

Habib, R., \& Dixon, M. R. (2010). Neurobehavioral evidence for the 'near-miss' effect in pathological gamblers. Journal of the Experimental Analysis of Behavior, 93(3), 313-328.

Haimson, B., Wilkinson, K. M., Rosenquist, C., Ouimet, C., \& McIlvane, W. J. (2009). Electrophysiological correlates of stimulus equivalence processes. Journal of the Experimental Analysis of Behavior, 92(2), 245-256.

Hantula, D. A. (2012). Consumers are foragers, not rational actors: towards a behavioral ecology of consumer choice. In V. Wells \& G. R. Foxall (Eds.), Handbook of developments in consumer behaviour (pp. 549577). Cheltenham: Edward Elgar.

Hantula, D. A. (2016). Editorial: a very special issue. The Behavior Analyst, 39(1), 1-5.

Hayes, S. C. (1991). The limits of technological talk. Journal of Applied Behavior Analysis, 24(3), 417-420.

Hineline, P. N. (2005). The aesthetics of behavioral arrangements. The Behavior Analyst, 28(1), 15-28.

Jarmolowicz, D. P., Reed, D. D., DiGennaro Reed, F. D., \& Bickel, W. K. (2016). The behavioral and neuroeconomics of reinforcer pathologies: implications for managerial and health decision making. Managerial and Decision Economics, 37(4-5), 274-293.

Keenan, M. (2016). The scientific image in behavior analysis. The Behavior Analyst, 39(1), 7-8.

Morris, E. K. (1985). Public information, dissemination, and behavior analysis. The Behavior Analyst, 8(1), 95-110.

Morris, E. K. (2014). Stop preaching to the choir, publish outside the box: a discussion. The Behavior Analyst, $37(2), 87-94$.

Navarro, A. D., \& Fantino, E. (2005). The sunk cost effect in pigeons and humans. Journal of the Experimental Analysis of Behavior, 83(1), 1-13.

Navarro, A. D., \& Fantino, E. (2009). The sunk-time effect: an exploration. Journal of Behavioral Decision Making, 22(3), 252-270.

Nevin, J. A., Mandell, C., \& Atak, J. R. (1983). The analysis of behavioral momentum. Journal of the Experimental Analysis of Behavior, 39(1), 49-59.

Nevin, J. A., \& Shahan, T. A. (2011). Behavioral momentum theory: equations and applications. Journal of Applied Behavior Analysis, 44(4), 877-895.

Quine, W. V. O. (1960). Word and object. Cambridge, MA: MIT Press.

Rachlin, H. (2016). Social cooperation and self-control. Managerial and Decision Economics, 37(4-5), 249260.

Rachlin, H., \& Green, L. (1972). Commitment, choice and self-control. Journal of the Experimental Analysis of Behavior, 17(1), 15-22.

Rebec, G. V., \& WenLin, S. (2005). Neuronal substra tes of relapse to cocaine-seeking behavior: role of prefrontal cortex. [Article]. Journal of the Experimental Analysis of Behavior, 84(3), 653-666.

Reed, D. D. (2014). Determining how, when, and whether you should publish outside the box: sober advice for early career behavior analysts. The Behavior Analyst, 37(2), 83-86.

Rorty, R. (1989). Contingency, irony, and solidarity. Cambridge, UK: Cambridge University Press.

Schlund, M. W., \& Cataldo, M. F. (2005). Integrating functional neuroimaging and human operant research: brain activation correlated with presentation of discriminative stimuli. Journal of the Experimental Analysis of Behavior, 84(3), 505-519.

Siegel, E., \& Rachlin, H. (1995). Soft commitment: self-control achieved by response persistence. Journal of the Experimental Analysis of Behavior, 64(2), 117-128.

Smith, J. M. (2016). Strategies to position behavior analysis as the contemporary science of what works in behavior change. The Behavior Analyst, 39(1), 75-87.

Springer, B., Brown, T., \& Duncan, P. K. (1981). Current measurement in applied behavior analysis. The Behavior Analyst, 4(1), 19-31.

Strumwasser, F. (1994). The relations between neuroscience and human behavioral science. Journal of the Experimental Analysis of Behavior, 61(2), 307-317.

Timberlake, W., Schaal, D. W., \& Steinmetz, J. E. (2005). Relating behavior and neuroscience: introduction and synopsis. Journal of the Experimental Analysis of Behavior, 84(3), 305-311.

Tuomisto, M. T., \& Parkkinen, L. (2012). Defining behavior-environment interactions: translating and developing an experimental and applied behavior-analytic vocabulary in and to the national language. Journal of the Experimental Analysis of Behavior, 97(3), 347-355. 
Vannorsdall, T. D., van Steenburgh, J. J., Schretlen, D. J., Jayatillake, R., Skolasky, R. L., \& Gordon, B. (2016). Reproducibility of tDCS results in a randomized trial: failure to replicate findings of tDCSinduced enhancement of verbal fluency. Cognitive and Behavioral Neurology, 29(1), 11-17.

VilliarreaI, R. P., \& Steinmetz, J. E. (2005). Neuroscience and learning: lessons from studying the involvement of a region of cerebellar cortex in eyeblink classical conditioning. Journal of the Experimental Analysis of Behavior, 84(3), 631-652.

Ward, R. D., Simpson, E. H., Kandel, E. R., \& Balsam, P. D. (2011). Modeling motivational deficits in mouse models of schizophrenia: behavior analysis as a guide for neuroscience. Behavioural Processes, 87(1), $149-156$.

Wilson, B. M., Mickes, L., Stolarz-Fantino, S., Evrard, M., \& Fantino, E. (2015). Increased false-memory susceptibility after mindfulness meditation. Psychological Science, 26(10), 1567-1573.

Wilson, B. M., Stolarz-Fantino, S., \& Fantino, E. (2013). Regulating the way to obesity: unintended consequences of limiting sugary drink sizes. Plos One, 8(4), e61081. 